Revue des patrimoines

\title{
La création de la collection de peintures murales du musée des Monuments français
}

\section{Laurence de Finance}

\section{(2) OpenEdition}

\section{Journals}

Édition électronique

URL : http://journals.openedition.org/insitu/10781

DOI : 10.4000/insitu. 10781

ISSN : 1630-7305

\section{Éditeur}

Ministère de la culture

Référence électronique

Laurence de Finance, «La création de la collection de peintures murales du musée des Monuments français », In Situ [En ligne], 22 | 2013, mis en ligne le 15 novembre 2013, consulté le 02 mai 2019. URL : http://journals.openedition.org/insitu/10781 ; DOI : 10.4000/insitu.10781

Ce document a été généré automatiquement le 2 mai 2019.

\section{(c) $($ i) $(9)$}

In Situ Revues des patrimoines est mis à disposition selon les termes de la licence Creative Commons Attribution - Pas d'Utilisation Commerciale - Pas de Modification 4.0 International. 


\title{
La création de la collection de peintures murales du musée des Monuments français
}

\author{
Laurence de Finance
}

1 Les quelques 350 peintures murales du musée ont été réalisées pour la majorité d'entre elles de 1937 à 1976 par une trentaine de peintres fresquistes sélectionnés avec circonspection par Paul Deschamps, afin que les œuvres reproduites correspondent le plus fidèlement possible à l'original.

2 La spécificité de la collection réside dans le parti-pris de reproduire les œuvres à l'échelle 1 et en volume pour les ensembles suffisamment bien conservés: la voûte de Saint-Savin-sur-Gartempe (Vienne), la crypte de Tavant (Indre-et-Loire), la chapelle de Saint-Chef (Isère), la crypte de la cathédrale d'Auxerre (Yonne), le chœur de l'église de Vic (Indre), la coupole occidentale de la cathédrale de Cahors (Tarn), etc. Ce choix de reproduction est alors à l'encontre de la politique de conservation de deux de nos pays limitrophes, favorables à la dépose des peintures: l'Italie, où les peintures des Stabies sont un des fleurons du musée de Naples, l'Espagne, où le musée d'art catalan ouvert en 1934 au palais de Montjuic à Barcelone présente des peintures romanes retirées des églises de Catalogne afin de les faire connaître et de les protéger du vandalisme. Ces peintures catalanes furent d'ailleurs présentées en 1937 au Jeu de Paume où elles remportèrent un réel succès auprès des Parisiens.

En France, la doctrine de la commission des Monuments historiques - dont une souscommission présidait à la constitution des collections du musée - était celle de la conservation in situ, ce qui induisait la commande quasi systématique de relevés, comme instruments de conservation et de restauration.

En 1934, le premier projet de Deschamps (1888-1974) alors conservateur du musée des Monuments français, avant d'en devenir le directeur, était d'exposer les relevés aquarellés, commandés par le service des Monuments historiques, réalisés en général au $\mathrm{XIX}^{\mathrm{e}}$ siècle, au $1 / 10^{\mathrm{e}}$ ou au quart des dimensions originelles. En raison de leur fragilité, cette solution fut écartée dès 1937 au profit de copies à grandeur plus "parlantes » pour 
le public. Les relevés s'adressent surtout aux professionnels; ils constituent davantage l'instrument d'une politique de conservation que le substitut d'une disparition envisagée. Ceux des peintures murales emblématiques commandés au XIX et au $\mathrm{XX}^{\mathrm{e}}$ siècle sont conservés à la médiathèque de l'architecture et du patrimoine, à Charenton-le-Pont (Valde-Marne) ${ }^{1}$.

Le 22 janvier 1937, Paul Deschamps, directeur du musée des Monuments français, présente officiellement à la Commission des Monuments historiques son projet d'ouvrir une galerie de reproductions de peintures murales et de vitraux à grandeur et dès janvier 1939 il annonce son intention de faire réaliser des peintures en volume. Son choix se porte immédiatement sur l'église de Saint-Savin-sur-Gartempe (Vienne) (fig. $\left.\mathbf{n}^{\circ} \mathbf{1}\right)$ dont on doit à Prosper Mérimée le dégagement des peintures dès 1838, l'obligation d'en dresser les relevés ${ }^{2}$ et le classement au titre des Monuments historiques sur la liste en 1840. C'est la présence de ces peintures à Saint-Savin qui incite l'historien d'art, Henri Focillon, à qualifier un siècle plus tard cet ensemble de «Sixtine romane » et à lui consacrer vingt pages de texte (soit un tiers du volume) et quarante planches d'illustrations dans son ouvrage paru en $1938^{3}$.

Figure 1

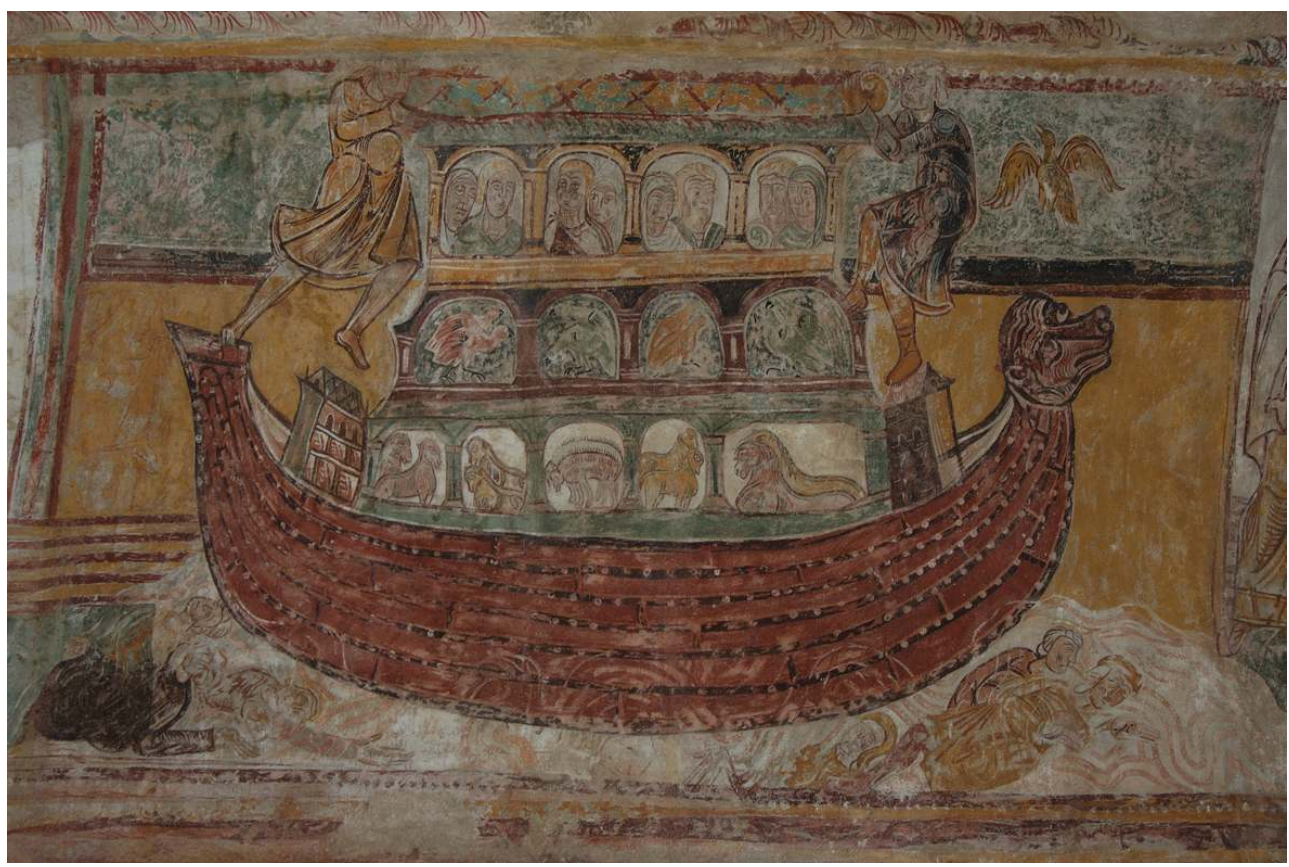

Musée des monuments français, Cité de l'architecture et du patrimoine. Arche de Noé, détail de la voûte de l'église abbatiale de Saint-Savin-sur-Gartempe (Vienne), fin XIe-début XIIe siècle.

Phot. Lomont, B. (c) CAPA/MMF.

Après une tentative de réalisation $a$ fresco dont témoignent quatre scènes encore visibles dans le hall du musée, c'est finalement la technique du marouflage qui sera privilégiée au musée, pour la voûte de Saint-Savin et pour l'ensemble de la galerie des peintures, à l'exception de celles de la crypte de Tavant.

Des documents et photographies anciennes permettent de reconstituer la muséographie mise en place par Paul Deschamps ${ }^{4}$ pour les inaugurations successives du «musée de la fresque » le 14 juin 1945 pour la partie romane, le 29 avril 1955 pour la peinture gothique, 
et le 9 mars 1959 - en présence d'André Malraux alors ministre de la Culture - pour les peintures murales de la Renaissance 5 .

Depuis 2007, le positionnement du musée des Monuments français, au sein de la Cité de l'architecture et du patrimoine, a entrainé l'installation d'une galerie consacrée à l'architecture moderne et contemporaine, celle d'une bibliothèque d'architecture et la création d'ateliers pédagogiques, obligeant les « galeries historiques » à mettre en réserve plusieurs moulages, peintures et vitraux. (fig. $n^{\circ} 2$ )

Figure 2

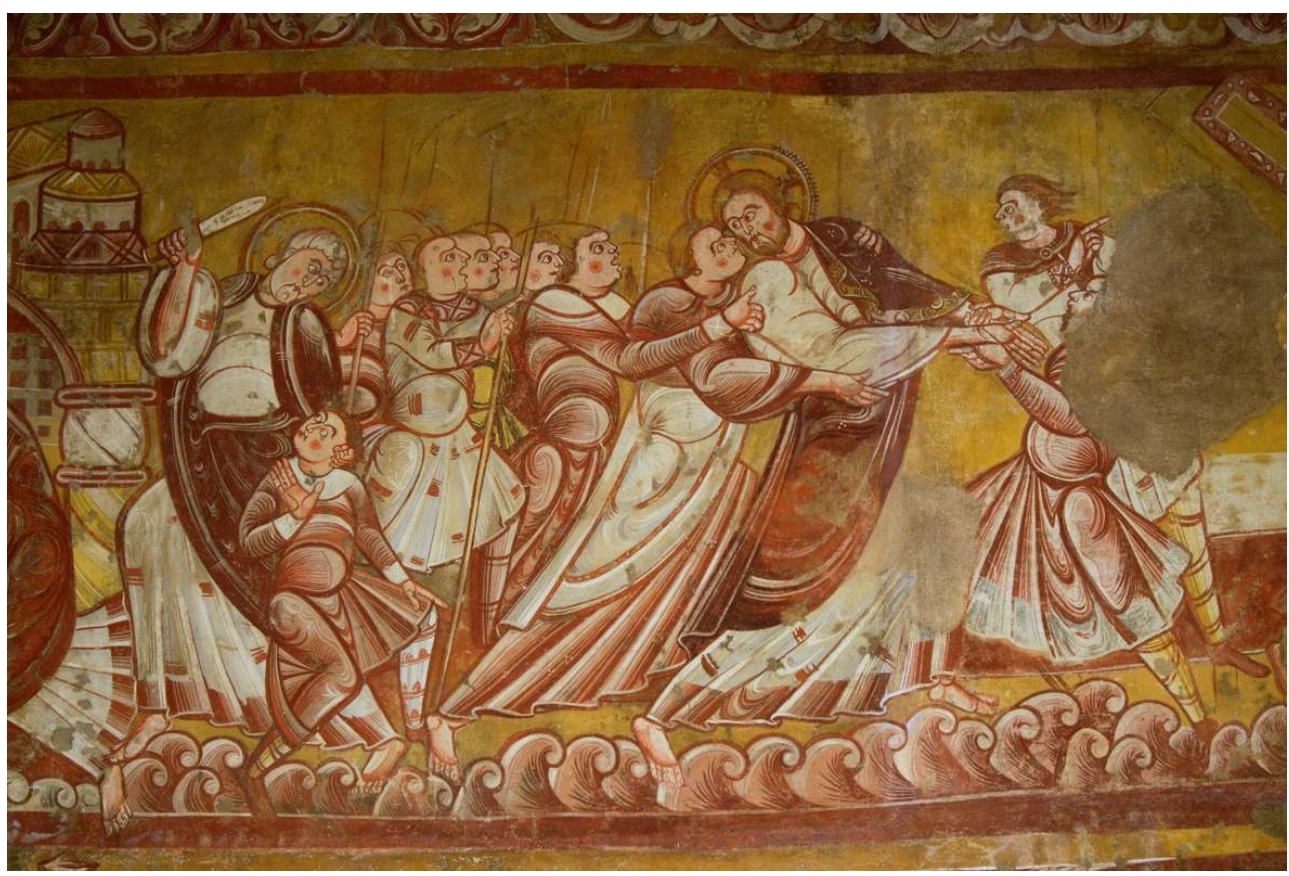

Musée des monuments français, Cité de l'architecture et du patrimoine. Baiser de Judas, église SaintMartin de Vic (Indre), $2^{\mathrm{e}}$ quart du XIIe siècle.

Phot. Lomont, B. (c) CAPA/MMF.

En entrant au musée des Monuments français, les reproductions qu'elles soient peintes, sculptées ou vitrées, perdent leur statut initial de copies et sont traitées comme des œuvres à part entière, leur état sanitaire est suivi de près par la régie des œuvres et le personnel de conservation. Correspondant à un temps T de l'œuvre originale, ayant leur vie propre, elles sont désormais regardées comme une étape de l'œuvre originale, postérieures aux restaurations des $\mathrm{XVIII}^{\mathrm{e}}$ et $\mathrm{XIX}^{\mathrm{e}}$ siècles, mais antérieures à celles des $\mathrm{XX}^{\mathrm{e}}$ et $\mathrm{XXI}^{\mathrm{e}}$ siècles. C'est une étape que connut l'œuvre originale mais qu'elle a aujourd'hui dépassée. La survenue au musée d'une éventuelle restauration, même minime (suite à un soulèvement d'écailles de la surface picturale, à un empoussièrement ou à une dégradation volontaire si minime soit-elle) est confiée aux restaurateurs agréés par le service des Monuments historiques. L'original entretient ainsi avec son double une sorte de dialogue imagé qu'il nous est donné de prolonger. 


\section{NOTES}

1. - Voir l'article de Jean-Daniel Pariset dans ce numéro : La collection de relevés de peintures murales de la Médiathèque de l'architecture et du patrimoine sous l'œil de la commission des monuments historiques.

2. - Lire sur le sujet l'article d'Élodie JEANNEST. «Les relevés de peintures murales de SaintSavin-sur-Gartempe aux XIX et $\mathrm{XX}^{\mathrm{e}}$ siècles : l'aquarelle au service de la restauration ». Bulletin monumental, 2011, t. 169/2, p. 115-126.

3. - FOCILLON, Henri. Les peintures romanes des églises de France. Paris : éd. Hartmann, 1938.

4. - Voir l'article de Carole Lenfant.

5. - Je remercie Emmanuelle Polack d'avoir retrouvé, dans les archives du musée, les affiches de ces différentes inaugurations.

\section{AUTEUR}

\section{LAURENCE DE FINANCE}

Conservatrice générale du patrimoine, directrice du Musée des monuments français, Cité de l'architecture et du patrimoine ldefinance@citechaillot.fr 